\title{
Brief psychological therapies for anxiety and depression in primary care: meta-analysis and meta-regression
}

\author{
John Cape ${ }^{* 1,2}$, Craig Whittington22, Marta Buszewicz ${ }^{3}$, Paul Wallace 3 and Lisa Underwood 4
}

\begin{abstract}
Background: Psychological therapies provided in primary care are usually briefer than in secondary care. There has been no recent comprehensive review comparing their effectiveness for common mental health problems. We aimed to compare the effectiveness of different types of brief psychological therapy administered within primary care across and between anxiety, depressive and mixed disorders.

Methods: Meta-analysis and meta-regression of randomized controlled trials of brief psychological therapies of adult patients with anxiety, depression or mixed common mental health problems treated in primary care compared to primary care treatment as usual.

Results: Thirty-four studies, involving 3962 patients, were included. Most were of brief cognitive behaviour therapy (CBT; $n=13)$, counselling $(n=8)$ or problem solving therapy (PST; $n=12)$. There was differential effectiveness between studies of CBT, with studies of CBT for anxiety disorders having a pooled effect size $[d-1.06,95 \%$ confidence interval $(C \mathrm{Cl})$ -1.31 to -0.80 ] greater than that of studies of CBT for depression $(d-0.33,95 \% \mathrm{Cl}-0.60$ to -0.06$)$ or studies of CBT for mixed anxiety and depression ( $d-0.26,95 \% \mathrm{Cl}-0.44$ to -0.08$)$. Counselling for depression and mixed anxiety and depression ( $d-0.32,95 \% \mathrm{Cl}-0.52$ to -0.11$)$ and problem solving therapy (PST) for depression and mixed anxiety and depression $(d-0.21,95 \% \mathrm{Cl}-0.37$ to -0.05$)$ were also effective. Controlling for diagnosis, meta-regression found no difference between CBT, counselling and PST.
\end{abstract}

Conclusions: Brief CBT, counselling and PST are all effective treatments in primary care, but effect sizes are low compared to longer length treatments. The exception is brief CBT for anxiety, which has comparable effect sizes.

\section{Background}

Anxiety and depressive disorders are common, with estimated combined prevalence varying between countries but over $10 \%$ in most Western countries [1-4]. The majority of such patients are treated in primary care, with few patients referred on to secondary mental health services [5,6].

With access to psychological therapies being limited [7], psychological therapy provided within primary care settings for depression and anxiety is usually brief [8]. In the UK, six sessions is a common treatment length [9]. This contrasts to the treatment lengths of $12-24$ sessions

\footnotetext{
*Correspondence: j.cape@ucl.ac.uk

${ }^{1}$ Camden and Islington NHS Foundation Trust, St Pancras Hospital, 4 St Pancras Way, London NW1 OPE, UK

Full list of author information is available at the end of the article
}

which have been the subject of most efficacy trials of psychological therapies in secondary care settings $[10,11]$.

Most reviews of psychological therapies combine primary and secondary care studies [11-13]. Recent reviews which have included analyses limited to primary care, have focussed on studies of patients with a diagnosis of depression [14-18] or studies of a specific type of psychological therapy [19]. Although studies of psychological therapies in primary care frequently include patients with both anxiety and depression, reflecting the heterogeneous patient presentations in primary care where mixed anxiety and depression is the most common diagnosis [20-22], such studies are excluded when the selection criteria for reviews are limited to single mental health diagnoses. The only reviews covering the range of mental 
health disorders and types of psychological therapies used within primary care date back over a decade [23-26].

This systematic review, meta-analysis and meta-regression includes studies of anxiety, depression and mixed common mental health problems. It compares the effectiveness of different types of brief psychological therapies within primary care across and between disorders compared to treatment as usual. In the absence of studies directly comparing different types of psychological therapy provided in primary care (with one exception [27]), such comparisons are needed to help inform decisions about treatment.

\section{Methods}

\section{Search strategy}

Studies were identified as part of a broader search of intervention studies in primary care mental health. The Medline, Embase and Psycinfo databases from inception to July 2008 were searched using a sensitive search strategy involving combinations of 'mental health' ('mental health' or psychol" or anx" or depress" or schizo" or dysthymi" or psychiatr* or emotion" or counsel") and 'primary care' terms ('primary care' or 'primary health care' or 'family physician*' or 'practice nurs"' or 'general pract"*' or GP*) in order to maximize identification of relevant interventions. Additional papers were identified from reference lists, from hand searching key journals and from contact with other primary care mental health researchers. All searches were limited to peer-reviewed published works in English.

\section{Inclusion criteria}

For this review, we included published randomized controlled trials of brief psychological therapies for adult patients with anxiety, depression, unspecified common mental health problems or 'emotional distress' provided by someone other than the patient's general practitioner (GP) either in primary care or at home organized from primary care. 'Brief' was operationalized as more than two and less than 10 appointments, this number being a pragmatic choice on the grounds that it clusters around the six sessions commonly offered in primary care in the UK and is clearly fewer than the $12-24$ sessions usually provided in secondary care efficacy trials. Studies of computerized or facilitated self-help [28-30], of psycho-educational groups [31,32], and of psychological therapy carried out as part of or referral on from case management within collaborative care [33], were excluded.

\section{Data extraction}

Data from included studies were extracted into structured summary tables. Studies were classified according to type of psychological therapy and whether patients included had major depressive disorder (MDD), minor depression, mixed depression, anxiety or 'mixed anxiety and depression' (where participants with a range of diagnoses of anxiety, depression, unspecified common mental health problems or 'emotional distress' were included). Outcome data closest to 4 months from baseline were extracted where there was more than one follow-up period, as this was the most common follow-up interval used in our initial set of studies. Other information extracted included: details of the participants; study country; length of follow-up (weeks from baseline); number of treatment sessions; study design (individually randomized or cluster randomized); method of randomization and allocation concealment; use of intention-to-treat analysis; primary symptom outcome measure(s); data of publication; number of participants randomized and attrition from each group. The data were initially extracted by one reviewer, with the results being checked by a second reviewer who extracted the outcome data independently, but otherwise was not blinded to the findings of the first reviewer. Disagreements between reviewers were resolved by discussion.

The quality of each study was assessed by one reviewer who examined the adequacy of randomization and allocation concealment, and attrition using a modified version of the SIGN quality checklist for randomized controlled trials [34]. A second reviewer, blinded to the findings of the first reviewer, checked a sample of papers for reliability of the quality assessment.

\section{Meta-analysis}

Comprehensive meta analysis (CMA) software, Version 2.2.040 [35] was used to calculate the standardized mean difference $(d)$ and associated standard error for each study, computed from means and standard deviations (adjusted for baseline differences if reported) or from the sample size and $P$-value from an appropriate betweengroups $t$ - or $F$-test if no other data were reported. We used data from an intention-to-treat analysis, with last observation carried forward, rather than data from participants who completed the study, if both were reported. Where a study only reported data from dichotomous outcomes (remission or response to treatment), we assumed that participants who ceased to engage in the study from whatever group - had an unfavourable outcome, then converted the log odds ratio into $d$ using CMA. For the purposes of the review, negative values of $d$ indicate that the outcome favoured the intervention. The metan command in Stata Version 9.2 [36] was used to produce forest plots and summary effects using a random-effects model.

We used $I^{2}$ and the $Q$ test of heterogeneity $[37,38]$ to examine among-study variation in the meta-analysis. Significant variation was confirmed by visual inspection of the forest plots. $I^{2}$ describes the proportion of total varia- 
tion in study effect sizes that is due to heterogeneity as opposed to sampling error, with $25 \%, 50 \%$ and $75 \%$ indicating low, moderate and high heterogeneity [38].

We conducted planned sub-group analyses based on both type of psychological therapy and diagnosis. Sensitivity analyses were used to examine how robust these findings were to assumptions made when calculating effect size.

To check for publication bias, CMA was used to generate funnel plots and Egger's regression asymmetry test [39]. Where asymmetry was detected, we assessed the potential impact of the publication bias using the Duval and Tweedie nonparametric 'trim and fill' method [40]. This method recalculates the effect size given the presence of publication bias.

\section{Meta-regression}

We used the metareg command in Stata, to conduct random-effects meta-regression analyses with restricted maximum likelihood estimation and the improved variance estimator of Knapp and Hartung [41]. Where data allowed, univariate models were used to examine whether there were differences between psychological therapies and between diagnostic categories in the magnitude of the treatment effect. In addition, where possible, we used multivariate models to control for the following study characteristics if they were shown to be potential moderators in univariate models: country; year of publication; number of sessions; total number of participants randomized; type of data (continuous versus dichotomous); allocation concealment; use of intention-to-treat analysis; and attrition. In our analyses, the regression coefficients are the estimated change in $d$ per unit change in each covariate.

\section{Results}

The flowchart outlining the search process is shown in Figure 1. It should be noted that this represents the entirety of the search, of which only a proportion related to psychological therapies in primary care. Thirty-four studies met our inclusion criteria. There were four studies excluded on basis of the psychological therapy being 10 sessions or more [42-45].

Details of the included studies are given in Table 1 . Twelve were of cognitive behaviour therapy (CBT) [4657], seven of counselling [58-64], one of interpersonal psychotherapy [65], one of psychodynamic psychotherapy [66] and 12 of problem solving therapy (PST) [67-78]. One study included both a CBT and a counselling intervention arm compared to a usual GP treatment control [27] and so in the meta-analysis the control group was halved to avoid double counting.

Of the 34 studies, 14 were of patients with depression (six MDD, four minor depression, four mixed depres- sion), seven were of anxiety disorders (three generalized anxiety disorder, three panic disorder, one mixed phobic disorders) and 13 studies were of patients with 'mixed anxiety and depression' (including patients with a range of diagnoses of anxiety, depression and unspecified common mental health problems).

Twenty-two of the 34 studies were carried out in UK primary care, five in the USA, two in the Netherlands, two in Australia, one in Sweden, one in Taiwan and one was a multi-site study in five European countries. All studies were randomized by the individual participant. Seven studies were published in the 1980s, 13 in the 1990 s and 14 in the present decade. In 14 studies the psychological therapy was conducted in the patients' usual general practice or primary care clinic location, in two studies over the telephone, in three studies at home, in four studies both at home and in other primary care settings and in 11 studies the psychological therapy was described as being carried out 'in a primary care setting', 'in a local health centre' or 'in primary care' without this being further specified. The control condition for all studies was usual GP care, supplemented in a few studies $[49-51,56,67,75,78]$ by the patient receiving some additional control intervention, for example placebo medication or a self-help booklet.

There was similar median treatment intensity of six to seven contacts with the patient in CBT, counselling and PST, with the single studies of interpersonal psychotherapy and psychodynamic psychotherapy each involving eight sessions of treatment. In terms of the length of follow up, there was some variation between psychological therapies (median 14 weeks for counselling, 13 weeks for CBT, and 12 weeks for PST) and also between the CBT for anxiety (12 weeks) and the CBT for depression studies (16 weeks).

Table 1 also gives details of the quality assessment of each study. The method of randomization was well covered (15\% of studies) or adequately addressed (85\%). Allocation concealment was unclear $(71 \%)$ in most studies. Sixteen (47\%) studies were analysed by intention-totreat (ITT), with the remainder either not using ITT analysis or this being unclear in the reported paper. Twentyone (62\%) studies reported less than $20 \%$ attrition across both groups with eight studies $(24 \%)$ reporting no attrition. In two studies $[62,70]$ there was $50 \%$ or more attrition from either group.

\section{Effect size of psychological therapies}

The meta-analysis showed small effects favouring brief CBT over usual GP care for both depression [ $d-0.33,95 \%$ confidence interval (CI) -0.60 to $-0.06, k=4, n=450)$ and mixed anxiety and depression $(d-0.26,95 \% \mathrm{CI}-0.44$ to $0.08, k=2, n=479$ ) and a larger effect for brief CBT for anxiety disorders (anxiety $d-1.06,95 \%$ CI -1.31 to $-0.80, k$ 


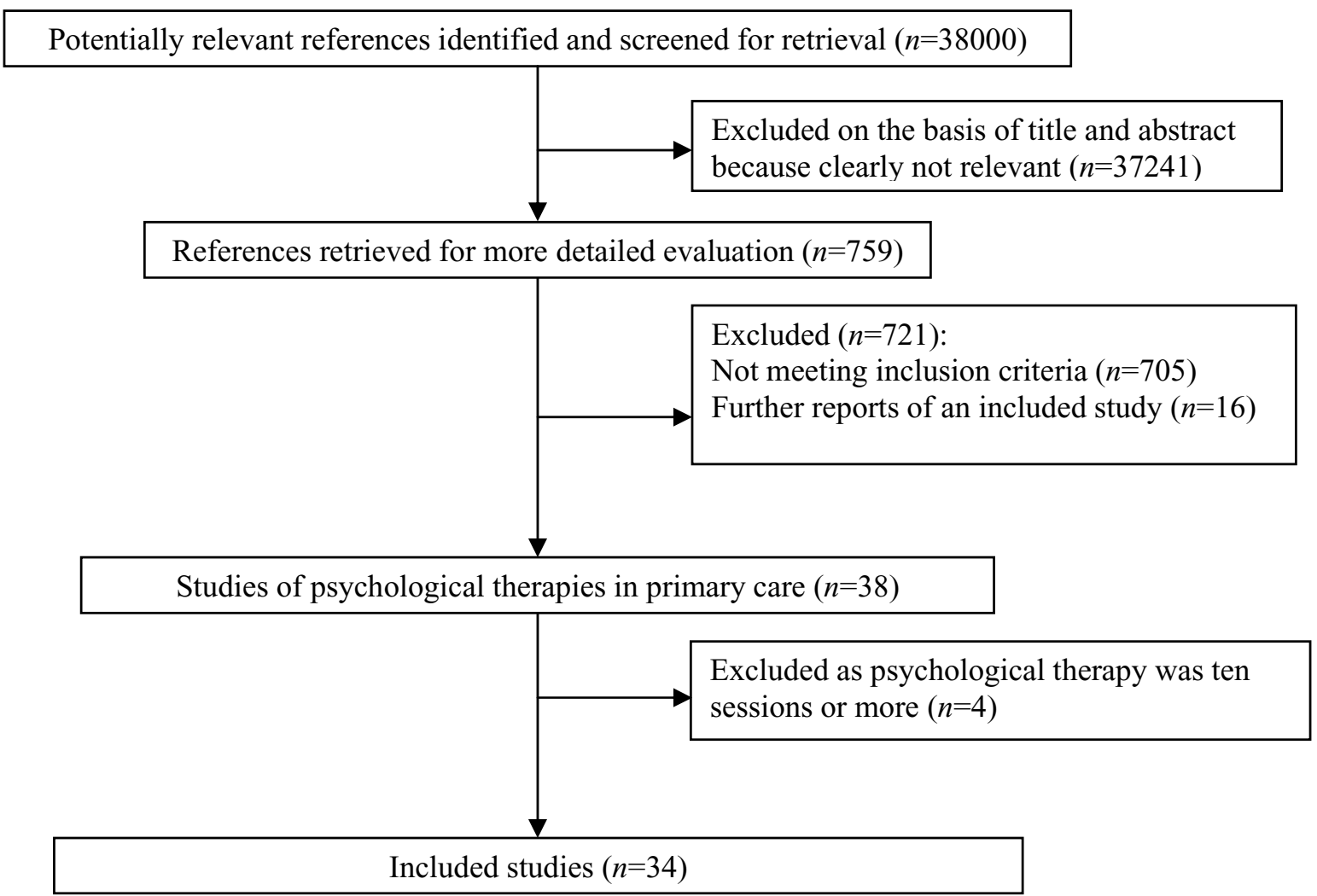

Figure 1 Results of literature searches and selection of randomized controlled trials for inclusion in the meta-analyses

$=7, n=450$; Figure 2). In each meta-analysis, heterogeneity between studies was low (CBT for depression $I^{2}=0 \%$, $Q=1.72, P=0.63$; CBT for mixed anxiety and depression $I^{2}=0 \%, Q=0.05, P=.83$; CBT for anxiety $I^{2}=15 \%, Q=$ 7.07, $P=0.32)$.

The meta-analysis suggested counselling was effective for mixed anxiety and depression $(d-0.30,95 \%$ CI -0.53 to $-0.07, k=4, n=487$ ), while the effect size for counselling for depression, although similar in size, fell short of statistical significance $(d-0.41,95 \%$ CI -0.84 to $0.03, k=4$, $n=359$; Figure 3 ). Heterogeneity between studies was moderate to high for the studies of depression $\left(I^{2}=63 \%\right.$, $Q=8.15, P=0.04)$ and low for mixed anxiety and depression $\left(I^{2}=31 \%, Q=4.37, P=0.22\right)$. There were no studies of counselling for anxiety disorders. Pooling across the studies of depression and mixed anxiety and depression, heterogeneity was intermediate $\left(I^{2}=44 \%, Q=12.55, P=\right.$ $0.04)$, with a small effect favouring counselling over usual GP care $(d-0.32,95 \%$ CI -0.52 to $-0.11, k=8, n=846)$.

The effect size was smaller for PST for both depression ( $d-0.26,95 \%$ CI -0.49 to $-0.03, k=5, n=777)$ and mixed anxiety and depression $(d-0.17,95 \%$ CI -0.41 to $-0.07, k=$ $6, n=579$; Figure 4). Heterogeneity between studies approached moderate for the studies of depression $\left(I^{2}=\right.$ $45 \%, Q=9.11, P=0.11$ ) and was moderate for mixed anx- iety and depression $\left(I^{2}=50 \%, Q=10.01, P=0.08\right)$. There were no studies of PST for anxiety disorders. Pooling across all studies produced a small effect favouring PST over usual GP care $(d-0.21,95 \%$ CI -0.37 to $-0.05, k=12$, $n=1356)$ with heterogeneity approaching a moderate level $\left(I^{2}=45 \%, Q=19.88, \mathrm{p}=0.05\right)$.

The evidence for interpersonal psychotherapy $(d-0.11$, -0.47 to $0.24, k=1, n=120)$ and psychodynamic psychotherapy $(d-0.01,95 \% \mathrm{CI}=-0.64$ to $0.63, k=1, n=38)$ was inconclusive, although only one small study was included for each of these in this review.

For the studies of depression and mixed anxiety and depression, a series of random-effects meta-regressions comparing types of psychological therapy, controlling for diagnosis, indicated there was no difference between CBT $(k=6)$ and counselling $(k=8$; regression coefficient -0.02, $P=.91$, adjusted $\left.R^{2}=0 \%, n=1584\right)$ or between CBT $(k=6)$ and PST $(k=12)$ (regression coefficient $0.10, P=$ 0.45 , adjusted $R^{2}=0 \%, n=2094$ ) or between counselling $(k=8)$ and PST $(k=12)$ (regression coefficient $0.10, P=$ 0.46 , adjusted $\left.R^{2}=0 \%, n=2202\right)$.

\section{Impact of diagnosis}

We conducted two sets of meta-regression analyses to explore the effect of diagnosis on the magnitude of the 


\begin{tabular}{|c|c|c|c|c|c|c|c|c|c|c|c|c|c|}
\hline \multirow[t]{2}{*}{ Study name } & \multicolumn{8}{|c|}{ Study characteristics } & \multicolumn{5}{|c|}{ Quality assessment } \\
\hline & $\mathbf{T x}$ & Country & Diag & Outcome & No. sessions & Type of data & FU (weeks) & Total N & Rand. & AC & ITT & $\%$ attrition (Intv) & $\%$ attrition $(\mathrm{Ctl})$ \\
\hline Barrett 2001 [67] & PST & USA & Dep - minor or dys & HDRS $<7$ & 6 & $\mathrm{D}$ & 11 & 161 & WC & WC & Y & 18 & 16 \\
\hline Boot 1994 [58] & $\mathrm{COU}$ & UK & Mixed Anx and Dep & GHQ & 6 & C & 6 & 192 & AA & U & $\mathrm{N}$ & 46 & 40 \\
\hline Brodaty 1983 [66] & $\mathrm{PP}$ & AUS & Mixed Anx and Dep & $\mathrm{GHQ}$ & 8 & C & 8 & 78 & AA & $\mathrm{U}$ & $\mathrm{N}$ & 65 & 26 \\
\hline Catalan 1991 [68] & PST & UK & Mixed Anx and Dep & PSE & 4 & $\mathrm{C}$ & 11 & 47 & $\mathrm{AA}$ & U & $\mathrm{N}$ & 0 & 0 \\
\hline Dowrick 2000 [69] & PST & EU & Dep - MDD or dys & $\mathrm{BDI}$ & 6 & C & 26 & 317 & $\mathrm{AA}$ & WC & Y & 23 & 26 \\
\hline Earll 1982 [46] & CBT & UK & Mixed Anx and Dep & $\mathrm{DSSI} / \mathrm{sAD}$ * & 7.7 & $\mathrm{D}$ & 32 & 50 & $A A$ & $U$ & $\mathrm{~N}$ & 16 & \\
\hline Friedli 1997 [59] & $\mathrm{COU}$ & UK & Mixed Anx and Dep & $\mathrm{BDI}$ & 9 & $\mathrm{C}$ & 12 & 136 & AA & $A A$ & Y & 16 & 23 \\
\hline Harvey 1998 [60] & $\mathrm{COU}$ & UK & Mixed Anx and Dep & HADS & 6 & $\mathrm{C}$ & 16 & 162 & AA & U & $Y$ & 31 & 25 \\
\hline $\begin{array}{l}\text { Hemmings } 1997 \\
\text { [61] }\end{array}$ & $\mathrm{COU}$ & UK & Mixed Anx and Dep & MHSI & 5.7 & C & 16 & 188 & AA & U & $\mathrm{N}$ & 16 & 23 \\
\hline Holden 1989 [62] & $\mathrm{COU}$ & UK & Dep - MDD & $\mathrm{RDC}$ & 8 & $\mathrm{D}$ & 12 & 50 & AA & U & $\mathrm{N}$ & 0 & 0 \\
\hline Kendrick 2005 [70] & PST & UK & Mixed Anx and Dep & CIS-R & 6 & C & 26 & 168 & WC & WC & Y & $20 \dagger$ & $31+$ \\
\hline Lang 2006 [71] & PST & USA & Mixed Anx and Dep & BSI-D & 4 & C & 12 & 62 & $A A$ & U & $Y$ & 34 & 17 \\
\hline Lindsay 1987 [47] & CBT & UK & Anx - GAD & GHQ-28 & 8 & C & 4 & 20 & $\mathrm{AA}$ & $U$ & $\mathrm{~N}$ & 0 & 0 \\
\hline Liu 2007 [72] & PST & TA & Mixed Anx and Dep & CIS-R & 2.27 & C & 16 & 169 & WC & AA & Y & 25 & 22 \\
\hline Lynch 1997 [73] & PST & USA & Dep-minor & HDRS & 6 & C & 7 & 29 & $A A$ & U & $\mathrm{N}$ & 27 & 7 \\
\hline Lynch 2004 [74] & PST & USA & Dep - minor & HDRS & 6 & C & 6 & 36 & AA & U & $\mathrm{N}$ & 50 & 28 \\
\hline Marks 1985 [48] & CBT & UK & Anx - phobic & PS & 6 & $\mathrm{C}$ & 26 & 92 & AA & $\mathrm{U}$ & $\mathrm{N}$ & 37 & 20 \\
\hline $\begin{array}{l}\text { Mynors-Wallis } \\
1995 \text { [75] }\end{array}$ & PST & UK & Dep - MDD & HDRS & 6 & C & 12 & 55 & AA & U & Y & 0 & 0 \\
\hline $\begin{array}{l}\text { Mynors-Wallis } \\
1997 \text { [76] }\end{array}$ & PST & UK & Mixed Anx and Dep & $\mathrm{CIS}$ & 4.5 & C & 26 & 70 & AA & AA & $\mathrm{N}$ & 20 & 13 \\
\hline Power 1989 [49] & CBT & UK & Anx - GAD & HAM-A & 4 & C & 6 & 21 & $\mathrm{AA}$ & $\mathrm{U}$ & Y & 0 & 0 \\
\hline Power 1990 [51] & CBT & UK & $A n x-G A D$ & $\mathrm{CGI}=1$ & 7 & $\mathrm{D}$ & 10 & 79 & $A A$ & U & $\mathrm{N}$ & 0 & 0 \\
\hline Power 2000 [50] & CBT & UK & Anx-panic & HAM-A & 6 & C & 12 & 72 & $\mathrm{AA}$ & $\mathrm{U}$ & $\mathrm{N}$ & 16 & 17 \\
\hline $\begin{array}{l}\text { Prendegast } 2001 \\
\text { [52] }\end{array}$ & CBT & AUS & Dep - mixed & EPDS $<10$ & 6 & $\mathrm{D}$ & 26 & 37 & AA & U & $\mathrm{N}$ & 0 & 0 \\
\hline Robson 1984 [53] & CBT & UK & Mixed Anx and Dep & PS & 3.7 & $\mathrm{C}$ & 14 & 429 & AA & U & $\mathrm{N}$ & $0+\dagger$ & $0+\dagger$ \\
\hline
\end{tabular}


Table 1: Details of included studies (Continued)

\begin{tabular}{|c|c|c|c|c|c|c|c|c|c|c|c|c|c|}
\hline $\begin{array}{l}\text { Schreuders } 2007 \\
\text { [77] }\end{array}$ & PST & NL & Mixed Anx and Dep & HADS & 6 & C & 12 & 175 & AA & WC & $\mathrm{N}$ & 30 & 22 \\
\hline Scott 1992 [54] & CBT & UK & Dep - MDD & HDRS & 9.8 & C & 16 & 60 & AA & AA & Y & 3 & 3 \\
\hline Scott 1997 [55] & CBT & UK & Dep - MDD & HDRS & 6 & C & 7 & 48 & AA & U & $\mathrm{N}$ & 25 & 33 \\
\hline Sharp 1996 [56] & CBT & UK & Anx-panic & HAM-A $\neq$ & 7 & D & 13 & 154 & AA & U & Y & $21^{\S}$ & $24 \S$ \\
\hline Sharp 2004 [57] & CBT & UK & Anx-panic & HAM-A & 8 & C & 12 & 59 & AA & U & $\mathrm{Y}$ & 16 & 14 \\
\hline Simpson 2003 [63] & $\mathrm{COU}$ & UK & Dep-mixed & BDI & 5 & C & 26 & 145 & AA & U & Y & 11 & 10 \\
\hline $\begin{array}{l}\text { Van Schaik } 2006 \\
\text { [65] }\end{array}$ & IPT & NL & Dep - MDD & MADRS & 8 & C & 26 & 143 & WC & WC & Y & 16 & 16 \\
\hline \multirow[t]{2}{*}{ Ward 2000 [27] } & CBT & UK & Dep-mixed & BDI & 5 & C & 16 & 197 & AA & U & Y & 11 & 8 \\
\hline & $\mathrm{COU}$ & & & & 6.4 & & & & & & & 8 & \\
\hline $\begin{array}{l}\text { Wickberg } 1996 \\
\text { [64] }\end{array}$ & $\mathrm{COU}$ & SW & Dep-mixed & MADRS ף & 6 & D & 7 & 45 & AA & U & $\mathrm{N}$ & 0 & 0 \\
\hline Williams 2000 [78] & PST & USA & Dep-minor or dys & HDRS $<7$ & 6 & D & 11 & 278 & WC & AA & Y & $18^{\S}$ & $15^{\S}$ \\
\hline
\end{tabular}

* Patients were categorized as not 'personally ill' by study authors.

** Number randomized to each group not reported by study authors.

+ We used missing data that were imputed from a regression analysis that took account of the baseline information for each participant with missing data rather than from last observation carried forward because of differential attrition between study groups.

${ }^{+t}$ Attrition not reported by study authors; therefore we assumed there was no missing data.

₹ Study authors defined response as a clinically significant change.

$\S$ For the purposes of the meta-analysis, participants with missing data were assumed to have had a poor outcome.

"Study authors defined response as a substantial improvement.

AA, adequately addressed; AC, allocation concealment; AUS, Australia; Anx, anxiety; BDI, Beck Depression Inventory; BSI-D, Brief Symptom Inventory - Depression scale; C, continuous; CBT, cognitive behavioural therapy; CES-D, Center for Epidemiologic Studies Depression Scale; CGI, Clinical Global Impression; CIS-R, Clinical Interview Schedule - Revised; COU, Counselling; CtI, control; D, dichotomous; Dep, depression; Dep - mixed, mixed depressive diagnoses including minor depression; Diag, diagnosis; DSSI/sAD, Delusions-Symptoms-States Inventory/states of Anxiety and Depression; dys, dysthymia; EPDS, Edinburgh Postnatal Depression Scale; EU, European countries; GHQ, General Health Questionnaire; HADS, Hospital Anxiety and Depression Scale; HAM-A, Hamilton Anxiety Rating Scale; HDRS, Hamilton Depression Rating Scale; Intv, intervention; IPT, Interpersonal psychotherapy; ITT, intention-to-treat analysis; MADRS, Montgomery-Åsberg Depression Rating Scale; MDD, major depressive disorder; MHSI, Mental Health Symptom index; Mixed Anx and Dep, mixed anxiety and depression diagnoses; N, number randomized; NL, Netherlands; PP, Psychodynamic psychotherapy; PS, psychiatric symptoms; PSE, Present State Examination; PST, problem solving therapy; Rand., randomization; RDC, Research Diagnostic Criteria; SW, Sweden; TA, Taiwan; Tx, treatment; U, unclear; WC, well covered; Y, yes. 


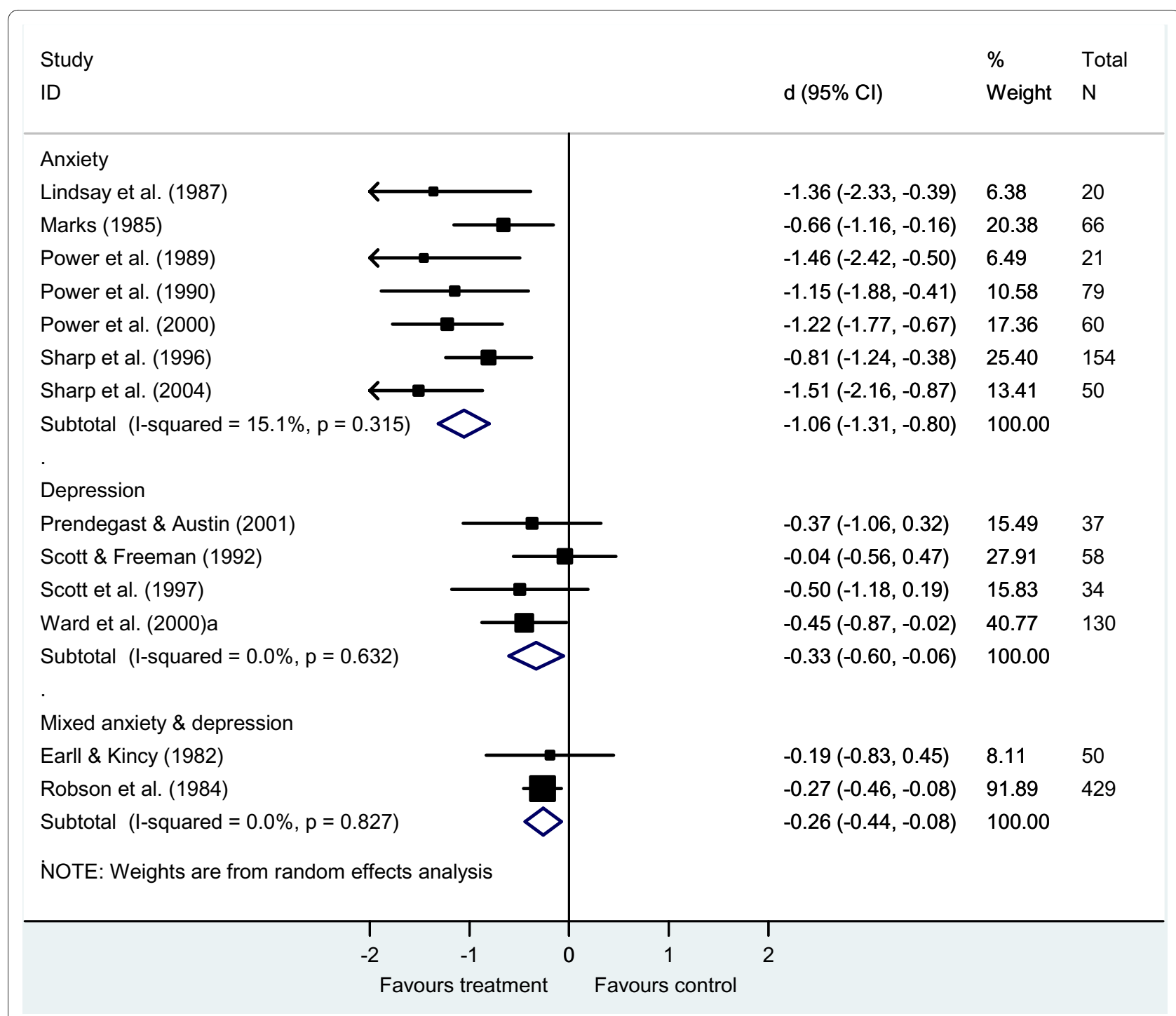

Figure 2 Brief cognitive behaviour therapy versus usual general practitioner care, sub-grouped by diagnosis

treatment effect. First, we looked at whether there was a difference between studies of anxiety, depression and mixed disorders in the 13 studies of CBT (Figure 2; Table 2). This analysis was limited to studies of CBT as all studies of anxiety disorders were of CBT. The results indicate that there was a statistically significant difference favouring the studies of anxiety $(k=7)$ over depression $(k=4$; regression coefficient $0.72, P=0.005$, adjusted $R^{2}=91 \%, n$ $=709$ ). There was also a significant difference favouring the studies of anxiety $(k=7)$ over mixed anxiety and depression $(k=2$; regression coefficient $0.79, P=0.003$, adjusted $\left.R^{2}=94 \%, n=929\right)$. There was no difference between the studies of depression $(k=4)$ and mixed anxiety and depression $(k=2$; regression coefficient $0.07, P=$ 0.70 , adjusted $R^{2}=0 \%, n=738$ ). In accordance with our planned analytic strategy, as no study characteristic other than diagnosis predicted effect size of CBT studies in the univariate models (Table 2), we did not use a multivariate meta-regression model.

Translating the effect sizes for CBT for anxiety and depression into Hamilton rating scale equivalents to give an indicator of clinical significance [using all studies in the database to estimate the Hamilton standard deviations], the effect size for CBT for depression was equivalent to a 2.3 point difference between groups on the Hamilton Rating Scale for Depression [79] while the effect size for CBT for anxiety was equivalent to 7.2 points on the Hamilton Rating Scale for Anxiety [80].

In the second set of meta-regressions, we examined whether the type of depression diagnosis had an impact on the treatment effect across types of psychological therapy. The results indicate that there was no significant 


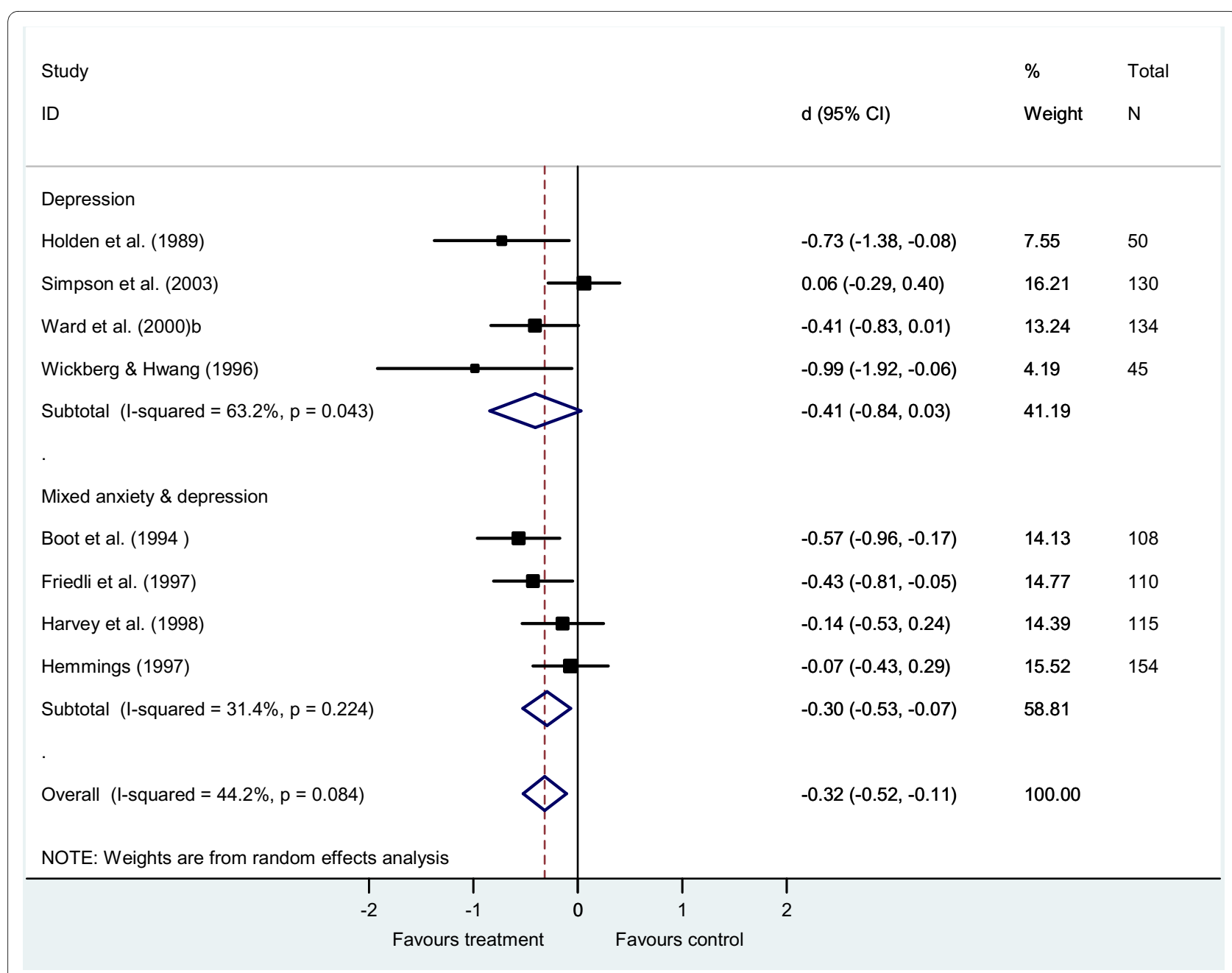

Figure 3 Brief counselling versus usual general practitioner care, sub-grouped by diagnosis.

difference between MDD $(k=6)$ and minor depression/ mixed depression $(k=9$; regression coefficient $0.12, P=$ 0.43 , adjusted $\left.R^{2}=2 \%, n=1515\right)$, or between minor depression $(k=4)$ and MDD/mixed depression $(k=11$; regression coefficient $-0.20, P=0.22$, adjusted $R^{2}=25 \%, n$ $=1515)$. No other study characteristic predicted effect size of the depression studies, so no multivariate metaregression was used.

\section{Publication bias}

Funnel plots of the CBT studies, showed evidence of asymmetry in the studies of CBT for anxiety (Egger's test, one-tailed $P=0.04$ ), but not CBT for depression/mixed anxiety and depression $(P=0.38)$. There was also evidence of asymmetry in the studies of counselling (onetailed $P=0.03$ ) and PST (one-tailed $P=0.03$ ). The Duval and Tweedie 'trim and fill' method suggested that, for CBT for anxiety, three studies were potentially missing and, if imputed, the overall summary effect would drop to $d-0.91$ (95\% CI -1.18 to -0.63). For counselling, imputing three missing studies reduced the effect size to $d-0.19$ (95\% CI -0.41 to -0.04 ). For PST, imputing two missing studies reduced the effect size to $d-0.14$ (95\% CI -0.32 to $-0.05)$.

\section{Discussion}

\section{Summary of main findings}

The majority of studies of brief psychological therapies for anxiety and depression in primary care included in this review were of CBT, counselling and PST, with a single study each of interpersonal psychotherapy and of psychodynamic psychotherapy. The meta-analysis suggests that brief CBT, counselling and PST were all effective. No significant difference was found between CBT, counselling and PST on meta-regression, when controlling for diagnosis,

Brief CBT for anxiety (mostly generalized anxiety disorder and panic disorder) had a greater impact on clinical outcomes than brief CBT for depression or of mixed groups of patients with common mental health problems, 


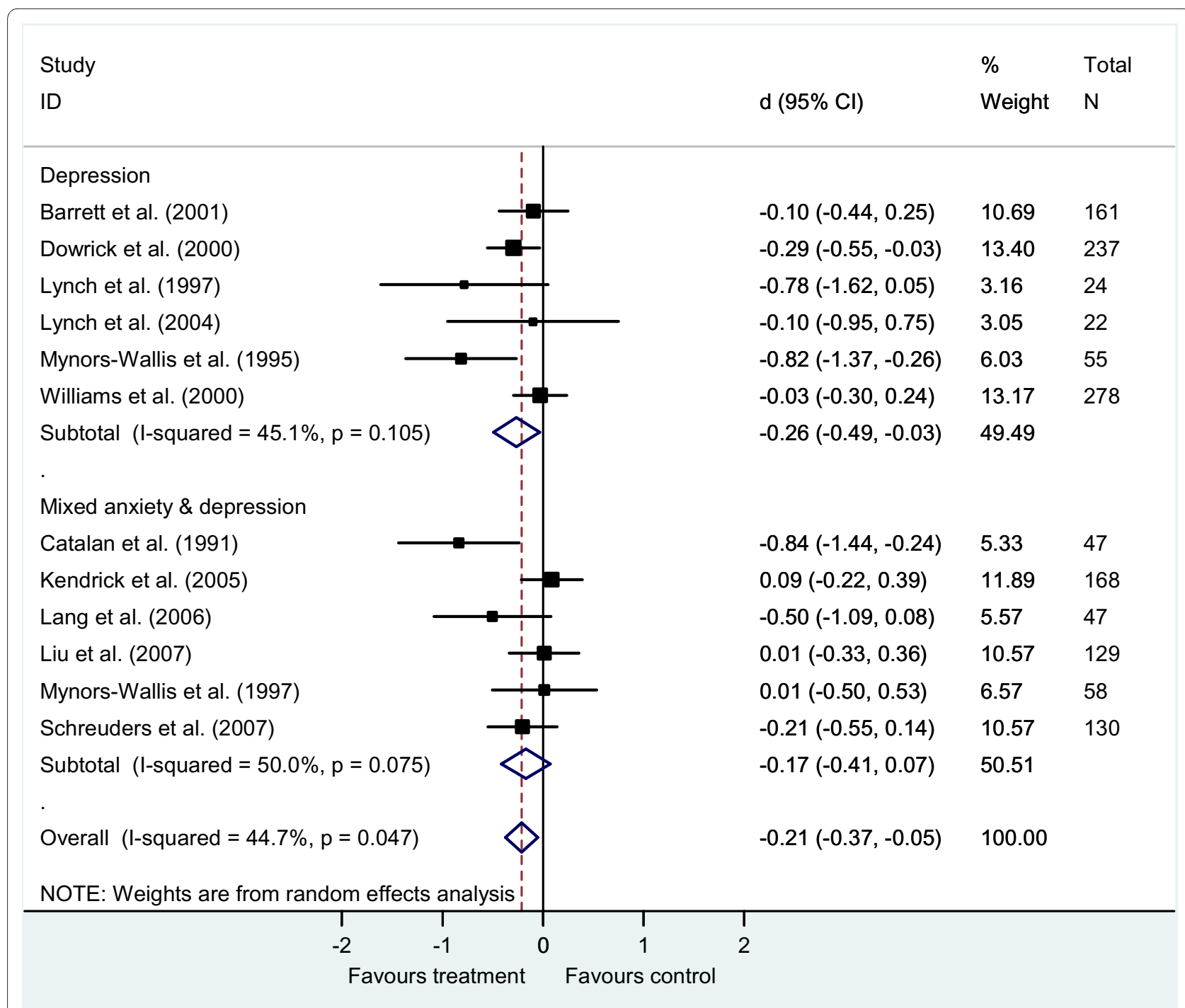

Figure 4 Brief problem solving therapy versus usual general practitioner care, sub-grouped by diagnosis.

for which the outcomes were similar to studies of counselling and of low clinical significance. There were no studies of counselling or PST for anxiety disorders alone, so it is not possible to establish from this review whether this is a specific differential effect of CBT or whether other brief psychological therapies might also have greater effects on anxiety than depression.

\section{Comparison with existing literature}

Reviews of CBT have generally found larger effect sizes compared to control for CBT as a treatment for anxiety disorders, with smaller effects obtained for CBT as a treatment for depression [12]. This is similar to the differential effect for brief CBT found in the present review. A recent review of internet-based $\mathrm{CBT}$ of anxiety and depression, also found differential effects between studies of internet-based CBT on depression and studies of inter- net-based CBT on anxiety [81], with remarkably similar effect sizes ( $d 0.27$ depression, $d 0.93$ anxiety) to those in the present review ( $d 0.33$ depression, $d 1.06$ anxiety).

The summary effects obtained were generally lower than reviews of secondary care based treatments, involving a longer duration of psychological therapies $[10,12,82]$. These differences in effect size could be due to a number of factors: length of treatment, type of included patients, training of therapists or location of treatment. In terms of type of included patients, participants in these primary care based studies may have had less severe conditions than those in secondary care based studies which would correspondingly limit the potential effect sizes. Brief CBT for anxiety disorders was the exception, with effect sizes in the present review comparable to those obtained in reviews of longer secondary care based treatments $[12,13]$. This may not be unique to primary care. In 
Table 2: Results of univariate meta-regressions for the 13 studies of cognitive behaviour therapy

\begin{tabular}{|c|c|c|c|c|c|c|c|c|}
\hline Variable & Category $1(k ; N)$ & Category $2(k ; N)$ & $\begin{array}{c}\text { Regression } \\
\text { coefficient }\end{array}$ & $\begin{array}{r}\begin{array}{r}\text { Standard } \\
\text { error }\end{array}\end{array}$ & $95 \% \mathrm{Cl}$ & $P^{*}$ & 12 & Adj $R^{2}$ \\
\hline \multicolumn{9}{|l|}{ Dichotomous } \\
\hline $\begin{array}{l}\text { Diagnosis } \\
\text { (model a) }\end{array}$ & Anxiety $=0(7 ; 497)$ & Depression $=1(4 ; 275)$ & .72 & .20 & $.28-1.16$ & .005 & $0 \%$ & $91 \%$ \\
\hline $\begin{array}{l}\text { Diagnosis } \\
\text { (model b) }\end{array}$ & Anxiety $=0(7 ; 497)$ & $\begin{array}{l}\text { Mixed anxiety \& } \\
\text { depression }=1(2,479)\end{array}$ & .80 & .18 & $.36-1.23$ & .003 & $2 \%$ & $94 \%$ \\
\hline $\begin{array}{l}\text { Diagnosis } \\
\text { (model c) }\end{array}$ & Depression $=0(4 ; 275)$ & $\begin{array}{l}\text { Mixed anxiety \& } \\
\text { depression }=1(2 ; 479)\end{array}$ & .07 & .17 & $-.39-.53$ & .70 & $0 \%$ & $0 \%$ \\
\hline Country & $\mathrm{UK}=0(12 ; 1214)$ & Other $=1(1 ; 37)$ & .36 & .56 & $-.87-1.58$ & 1.00 & $71 \%$ & $0 \%$ \\
\hline Type of data & Continuous $=0(9 ; 931)$ & Dichotomous $=1(4 ; 320)$ & -.11 & .31 & $-.79-.58$ & 1.00 & $70 \%$ & $0 \%$ \\
\hline Continuous & Range $(k ; N)$ & & & & & & & \\
\hline $\begin{array}{l}\text { Number of } \\
\text { sessions }\end{array}$ & $3.7-9.8(13 ; 1251)$ & & -.03 & .08 & $-.21-.15$ & 1.00 & $65 \%$ & $0 \%$ \\
\hline $\begin{array}{l}\text { Follow up } \\
\text { (weeks) }\end{array}$ & $4-31.6(13 ; 1251)$ & & .03 & .02 & $-.003-.07$ & .46 & $67 \%$ & $22 \%$ \\
\hline $\begin{array}{l}\text { Year of } \\
\text { publication }\end{array}$ & $1982-2004(13 ; 1251)$ & & -.02 & .02 & $-.06-.02$ & .89 & $59 \%$ & $16 \%$ \\
\hline $\begin{array}{l}\text { Number } \\
\text { randomized }\end{array}$ & $20-429(13 ; 1251)$ & & .001 & .001 & $-.001-.004$ & .89 & $59 \%$ & $7 \%$ \\
\hline $\begin{array}{l}\text { Attrition } \\
\text { (intervention } \\
\text { group) }\end{array}$ & $0-37 \%(13 ; 1251)$ & & -.01 & .01 & $-.03-.02$ & 1.00 & $67 \%$ & $0 \%$ \\
\hline $\begin{array}{l}\text { Attrition } \\
\text { (control group) }\end{array}$ & $0-33 \%(13 ; 1251)$ & & -.01 & .01 & $-.04-.03$ & 1.00 & $67 \%$ & $0 \%$ \\
\hline Study quality & $1-4(13,1251)$ & & .16 & .22 & $-.31-.64$ & 1.00 & $71 \%$ & $0 \%$ \\
\hline
\end{tabular}

secondary care, a direct comparison of brief and standard length CBT for panic disorder found equivalent effectiveness [83].

\section{Strengths and limitations of the study}

The strengths of the review are the inclusion of studies of representative populations of primary care patients, including with mixed anxiety and depression, and the use of meta-regression to compare effectiveness between different types of problems and different types of psychological therapy.

Limitations are the restriction to published studies and to English language publications. Other relevant studies may have been missed, particularly negative studies leading to an overestimation of the effects of brief psychological therapies. We did find evidence of possible publication bias and that accounting for this would have reduced effect sizes, although not changed the key conclusions of the review. Type of outcome measures, number of treatment sessions, follow-up intervals, country, number of participants randomized and aspects of study quality varied between studies, increasing heterogeneity and, hence, decreasing the likelihood of finding differences between types of psychological therapy and different diagnoses. Meta-regression ideally requires large numbers of studies and the sample size of studies in the review may have been too small to show other than relatively large effect size differences between types of psychological therapy.

The majority of studies in the meta-analysis used questionnaires and rating scales as outcome measures. Although this is standard in measurement of depression and anxiety outcomes, responses to such measures can vary between gender, language, culture and setting and are only a proxy for diagnosis. When analysed as continuous measures, there are potential problems caused by lack of interval-scaling, which may result in a sigmoidal, rather than linear, relationship between the score and the underlying trait [84]. Dependence on such measures in the meta-analysis is likely to have increased measurement error and heterogeneity [85]. They may also have led to systematic biases in the meta-regression where groups 
being compared (for example, patients with MDD versus minor and mixed depression) were using different measures or had baseline differences on the same measure.

A further limitation is the likely variation in locations included as 'primary care'. Reviews of psychological therapies in primary care vary in definitions as to what is included as primary care, with some reviews including studies if patients are recruited in or referred from primary care irrespective of where patients are treated. We set out to include studies where patients were treated either in a primary care setting or at home organized from primary care, but many study reports lacked details of where patients were seen other than 'in a primary care setting'. The significance of treatment in primary care is considered to be familiarity and accessibility of location and ease of liaison between GP and treating psychological therapist but this will quite probably have varied widely, given that studies varied from only one or two patients treated per participating general practice $[55,56,75]$, to a few hundred [53]. Better reporting of location of treatment and nature of liaison with patients' GPs should be encouraged in studies of treatment in primary care.

\section{Conclusions}

This review confirms the effectiveness of brief CBT, counselling and PST for routine delivery in primary care but with the caution that effect sizes are low when compared to patients receiving these treatments over a longer duration, so for many patients brief treatments may not be sufficient. The exception is brief CBT for anxiety disorders, which was comparable in effectiveness to longer treatments. While this suggests that brief CBT is particularly effective with anxiety disorders and there is evidence that training in CBT may enhance effectiveness of treatment of anxiety disorders by counsellors [86], the lack of randomized studies of brief psychological therapies other than CBT for patients suffering from anxiety disorders means that it is not possible to definitively determine whether brief CBT is more effective than other brief psychological treatments for anxiety disorders within primary care.

\footnotetext{
Abbreviations

CBT: cognitive behaviour therapy; CMA: comprehensive meta analysis; GP: general practitioner; ITT: intention-to-treat; MDD: major depressive disorders; PST: problem solving therapy.
}

\section{Competing interests}

The authors declare that they have no competing interests.

\section{Authors' contributions}

JC, MB, PW and CW conceived and designed the study. JC contributed to the literature searches. CW, JC and LU extracted the data. CW analysed the data. JC wrote the initial draft of the manuscript. MB, PW and CW contributed to the revision of the manuscript. All authors read and approved the final manuscript.

\section{Acknowledgements}

We thank Andrew Brown who contributed to the initial literature searches and Camden Primary Care Trust and Islington Primary Care Trust for funding the literature reviews.

\section{Author Details}

${ }^{1}$ Camden and Islington NHS Foundation Trust, St Pancras Hospital, 4 St Pancras Way, London NW1 OPE, UK, 2Research Department of Clinical, Educational and Health Psychology, University College London, Gower Street, London WC1E 6BT, UK, ${ }^{3}$ Research Department of Primary Care and Population Health, University College London Medical School, 2nd floor, Holborn Union Building, Archway Campus, Highgate Hill, London, N19 5LW, UK and ${ }^{4}$ Health Service and Population Research Department, Institute of Psychiatry, Kings College London, De Crespigny Park, London SE5 8AF, UK

Received: 20 May 2010 Accepted: 25 June 2010

Published: 25 June 2010

\section{References}

1. The WHO World Mental Health Survey Consortium: Prevalence, severity, and unmet need for treatment of mental disorders in the World Health Organization world mental health surveys. JAMA 2004, 291:2581-2590.

2. ESEMeD/MHEDEA 2000 Investigators: Prevalence of mental health disorders in Europe: results from the European Study of the Epidemiology of Mental Disorders (ESEMeD) project. Acta Psychiatr Scand 2004, 109(Suppl 420):21-27.

3. Kessler RC, Wang PS: The descriptive epidemiology of commonly occurring mental disorders in the United States. Annu Rev Public Health 2008, 29:115-129.

4. McManus S, Meltzer H, Brugha T, Bebbington P, Jenkins R: Adult Psychiatric Morbidity in England, 2007: Results of a Household Survey. Leeds: NHS Information Centre; 2009.

5. Goldberg D, Huxley P: Common Mental Disorders: A Bio-Social Model. London: Routledge; 1992.

6. Regier DA, Narrow WE, Rae DS, Manderscheid RW, Locke BZ, Goodwin FK: The de facto US mental and addictive disorders service system: Epidemiological Catchment Area prospective 1-year prevalence rates of disorders and services. Arch Gen Psychiatry 1993, 50:85-94.

7. Layard R: The case for psychological treatment centres. BMJ 2006, 332:1030-1032.

8. Thomas RV, Corney RH: A survey of the links between mental health professionals and general practice in six district health authorities. $\mathrm{Br} J$ Gen Pract 1992, 42:358-361.

9. Stiles WB, Barkham M, Connell J, Mellor-Clark J: Responsive regulation of treatment duration in routine practice in United Kingdom primary care settings: replication in a larger sample. J Consult Clin Psychol 2008, 276:298-305.

10. Drew W, Morrison K: A multidimensional meta-analysis of treatments for depression, panic, and generalized anxiety disorder: an empirical examination of the status of empirically supported therapies. J Consult Clin Psychol 2001, 69:875-899.

11. Roth A, Fonagy P: What Works For Whom? A Critical Review of Psychotherapy Research. 2nd revised edition. New York: Guilford; 2005.

12. Butler AC, Chapman JE, Forman EM, Beck AT: The empirical status of cognitive-behavioral therapy: A review of meta-analyses. Clin Psychol Rev 2006, 26:17-31.

13. Hofmann SG, Smits JA: Cognitive-behavioural therapy for adult anxiety disorders: a meta-analysis of randomized placebo-controlled trials. $J$ Clin Psychiatry 2008, 69:621-632.

14. Schulberg HC, Raue PJ, Rollman BL: The effectiveness of psychotherapy in treating depressive disorders in primary care practice: clinical and cost perspectives. Gen Hosp Psychiatry 2002, 24:203-212.

15. Smit A, Tiemens BG, Ormel J: Improving long-term outcome of depression in primary care: a review of RCTs with psychological and supportive interventions. Eur J Psychiatry 2007, 21:37-48.

16. Bortolotti B, Menchetti M, Bellini F, Montaguti MB, Berardi D: Psychological interventions for major depression in primary care: a meta-analytic review of randomized controlled trials. Gen Hosp Psychiatry 2008, 30:203-212

17. Wolf NJ, Hopko DR: Psychosocial and pharmacological interventions for depressed adults in primary care: a critical review. Clin Psychol Rev 2008, 28:131-161.

18. Cuijpers P, van Straten A, van Sciak A, Andersson G: Psychological treatment of depression in primary care: a meta-analysis. Br J Gen Pract 2009. DOI: 10.3399/bjgp09X395139

19. Bower $P$, Rowland $N$, Hardy R: The clinical effectiveness of counselling in primary care: a systematic review and meta-analysis. Psychol Med 2003, 33:293-302. 
20. Kessler RC, Chiu WT, Demler O, Merikangas KR, Walters EE: Prevalence, severity, and comorbidity of 12-month DSM-IV disorders in the National Comorbidity Survey Replication. Arch Gen Psychiatry 2005, 62:617-627.

21. Das-Munshi J, Goldberg D, Bebbington P, Bhugra D, Brugha T, Dewey M, Jenkins R, Stewart R, Prince P: Public health significance of mixed anxiety and depression: beyond current classification. Br J Psychiatry 2008, 192:171-177.

22. Kvaal K, McDougall FA, Brayne C, Matthews FE, Dewey ME, CFAS MRC: Cooccurrence of anxiety and depressive disorders in a community sample of older people: results from the MRC CFAS (Medical Research Council Cognitive Function and Ageing Study). Int $J$ Geriatr Psychiatry 2008, 23:229-237.

23. Balestrieri M, Williams $P$, Wilkinson G: Specialist mental health treatment in general practice: a meta-analysis. Psychol Med 1988, 18:711-717.

24. Brown C, Schulberg H: The efficacy of psychosocial treatments in primary care: a review of randomized trials. Gen Hosp Psychiatry 1995, $17: 414-424$

25. Friedli K, King M: Counselling in general practice - a review. Primary Care Psychiatry 1996, 2:205-216.

26. Hemmings A: A systematic review of the effectiveness of brief psychological therapies in primary health care. Families Systems and Health 2000, 18:279-313

27. Ward E, King M, Lloyd M, Bower P, Sibbald B, Farrelly S, Gabbay M, Tarrier N, Addington-Hall J: Randomised controlled trial of non-directive counselling, cognitive-behaviour therapy, and usual general practitioner care for patients with depression. I: Clinical effectiveness. BMJ 2000, 321:1383-1388.

28. Willemse GR, Smit F, Cuijpers P, Tiemens AG: Minimal-contact psychotherapy for sub-threshold depression in primary care: randomised trial. Br J Psychiatry 2004, 185:416-421.

29. Kaltenthaler E, Brazier J, De Nigris E, Tumur I: Computerised cognitive behaviour therapy for depression and anxiety update: a systematic review and economic evaluation. Health Technol Assess 2006, 10:1-186

30. Gellatly J, Bower P, Hennessy S, Richards D, Gilbody S, Lovell K: What makes self-help interventions effective in the management of depressive symptoms? Meta-analysis and meta-regression. Psychol Med 2007, 37:1217-1228.

31. Honey KL, Bennett P, Morgan M: A brief psycho-educational group intervention for postnatal depression. Br J Clin Psychol 2002, 41:405-409.

32. Hansson M, Bodlund O, Chotai J: Patient education and group counselling to improve the treatment of depression in primary care: a randomized controlled trial. J Affect Dis 2008, 105:235-240.

33. Gilbody S, Bower P, Fletcher J, Richards D, Sutton AJ: Collaborative care for depression: a cumulative meta-analysis and review of longer-term outcomes. Arch Intern Med 2006, 166:2314-2321.

34. Scottish Intercollegiate Guidelines Network: SIGN 50: A Guideline Developer's Handbook. Edinburgh: SIGN; 2004.

35. Borenstein M, Hedges L, Higgins J, Rothstein H: Comprehensive Metaanalysis Version 2 [Computer software]. Englewood, NJ: Biostat; 2005.

36. StataCorp: Stata Statistical Software: Release 9.2 [Computer software] College Station, TX: StataCorp; 2007.

37. Higgins J, Thompson S: Quantifying homogeneity in a meta-analysis. Stat Med 2002, 21:1539-1558.

38. Higgins J, Thompson S, Deeks J, Altman D: Measuring inconsistency in meta-analyses. BMJ 2003, 327:557-560

39. Egger M, Smith G, Schneider M, Minder C: Bias in meta-analysis detected by a simple, graphical test. BMJ 1997, 315:629-634.

40. Duval S, Tweedie R: A nonparametric 'trim and fill' method of accounting for publication bias in meta-analysis. J Am Stat Assoc 2000 95:89-98.

41. Knapp G, Hartung J: Improved tests for a random effects metaregression with a single covariate. Stat Med 2003, 22:2693-2710

42. Teasdale J, Fennel M, Hibbert G, Amies P: Cognitive therapy for major depressive disorder in primary care. Br J Psychiatry 1984, 144:400-406.

43. Ross M, Scott M: An evaluation of the effectiveness of individual and group cognitive therapy in the treatment of depressed patients in an inner city health centre. J R Coll Gen Pract 1985, 35:239-42.

44. Schulberg HC, Block MR, Madonia MJ, Scott CP, Rodriguez E, Imber SD, Perel J, Lave J, Houck PR, Coulehan JL: Treating major depression in primary care practice. Eight-month clinical outcomes. Arch Gen Psychiatry 1996, 53:913-919.
45. Wiles NJ, Hollinghurst S, Mason V, Musa M, Burt V, Hyde J, Jerrom B, Lewis $G$, Kessler D: A randomized controlled trial of cognitive behavioural therapy as an adjunct to pharmacotherapy in primary care based patients with treatment resistant depression: a pilot study. Behav Cog Psychother 2008, 36:21-33.

46. Earll L, Kincey J: Clinical psychology in general practice: a controlled trial evaluation. J R Coll Gen Pract 1982, 32:32-7.

47. Lindsay WR, Gamsu CV, McLaughlin E, Hood EM, Espie CA: A controlled trial of treatments for generalized anxiety. Br J Clin Psychol 1987 26:3-15.

48. Marks I: Controlled trial of psychiatric nurse therapists in primary care. BMJ 1985, 290:1181-1184

49. Power KG, Jerrom DWA, Simpson RJ, Mitchell MJ, Swanson V: A controlled comparison cognitive-behavior therapy, diazepam and placebo in the management of generalized anxiety. Behav Psychother 1989, 17:1-14.

50. Power KG, Sharp DM, Swanson V, Simpson RJ: Therapist contact in cognitive behaviour therapy for panic disorder and agoraphobia in primary care. Clin Psychol Psychother 2000, 7:37-46.

51. Power KG, Simpson RJ, Swanson V, Wallace LA: Controlled comparison of pharmacological and psychological treatment of generalized anxiety disorder in primary care. Br J Gen Pract 1990, 40:289-294.

52. Prendegast J, Austin MP: Early childhood nurse-delivered cognitive behavioural counselling for postnatal depression. Australasian Psychiatry 2001, 9:255-259.

53. Robson MH, France R, Bland M: Clinical psychologist in primary care: controlled clinical and economic evaluation. BMJ 1984, 288:1805-1808.

54. Scott AIF, Freeman CPL: Edinburgh primary care depression study: treatment outcome, patient satisfaction, and cost after 16 weeks. BMJ 1992, 304:883-887.

55. Scott C, Tacchi J, Jones R, Scott J: Acute and one-year outcome of a randomised controlled trial of brief cognitive therapy for major depressive disorder in primary care. Br J Psychiatry 1997, 171:131-134.

56. Sharp DM, Power KG, Simpson RJ, Swanson V, Moodie E, Anstee JA, Ashford JJ: Fluvoxamine, placebo, and cognitive behaviour therapy used alone and in combination in the treatment of panic disorder and agoraphobia. J Anxiety Disord 1996, 10:219-242.

57. Sharp DM, Power KG, Swanson V: A comparison of the efficacy and acceptability of group versus individual cognitive behaviour therapy in the treatment of panic disorder and agoraphobia in primary care. Clin Psychol Psychother 2004, 11:73-82.

58. Boot D, Gillies P, Fenelon J, Reubin R, Wilkins M, Gray P: Evaluation of the short-term impact of counselling in general practice. Patient Education and Counseling 1994, 24:79-89.

59. Friedli K, King M, Lloyd M, Horder J: Randomised controlled assessment of non-directive psychotherapy versus routine general practitioner care. Lancet 1997, 350:1662-1665.

60. Harvey I, Nelson SJ, Lyons RA, Unwin C, Monaghan S, Peters TJ: A randomized controlled trial and economic evaluation of counselling in primary care. Br J Gen Pract 1998, 48:1043-1048.

61. Hemmings A: Counselling in primary care: A randomised controlled trial. Patient Education and Counseling 1997, 32:219-230.

62. Holden JM, Sagovsky R, Cox JL: Counselling in a general practice setting: controlled study of health visitor intervention in treatment of postnatal depression. BMJ 1989, 298:223-226.

63. Simpson S, Corney R, Fitzgerald P, Beecham J: A randomized controlled trial to evaluate the effectiveness and cost-effectiveness of psychodynamic counselling for general practice patients with chronic depression. Psychol Med 2003, 33:229-239.

64. Wickberg B, Hwang CP: Counselling of postnatal depression: A controlled study on a population based Swedish sample. J Affect Dis 1996, 39:209-216.

65. Van Schaik A, van Marwijk H, Ader H, van Dyck R, de Haan M, Penninx B, van der Kooij K, van Hout H, Beekman A: Interpersonal psychotherapy for elderly patients in primary care. Am J Geriatr Psychiatry 2006, 14:777-786

66. Brodaty $\mathrm{H}$, Andrews $\mathrm{G}$ : Brief psychotherapy in family practice: a controlled prospective intervention trial. Br J Psychiatry 1983, 143:1 1-19.

67. Barrett JE, Williams JWJ, Oxman TE, Frank E, Katon W, Sullivan M, Hegel MT, Cornell JE, Sengupta AS: Treatment of dysthymia and minor depression in primary care: A randomized trial in patients aged 18 to 59 years. $J$ Fam Pract 2001, 50:405-412. 
68. Catalan J, Gath D, Anastasiades P, Bond A, Day A, Hall L: Evaluation of a brief psychological treatment for emotional disorders in primary care. Psychol Med 1991, 21:1013-1018.

69. Dowrick C, Dunn G, Ayuso-Mateos JL, Dalgard OS, Page H, Lehtinen V, Casey P, Wilkinson C, Vazquez-Barquero JL, Wilikinson G, the Outcomes of Depression International Network (ODON) Group: Problem solving treatment and group psychoeducation for depression: multicentre randomised controlled trial. Outcomes of Depression International Network (ODIN) Group. BMJ 2000, 321:1450-1454.

70. Kendrick T, Simons L, Mynors-Wallis L, Gray A, Lathlean J, Pickering R, Harris S, Rivero-Arias O, Gerard K, Thompson C: A trial of problem-solving by community mental health nurses for anxiety, depression and life difficulties among general practice patients. The CPN-GP study. Health Technol Assess 2005, 9(37):1-104. iii

71. Lang AJ, Norman GJ, Casmar PV: A randomized trial of a brief mental health intervention for primary care patients. J Consult Clin Psychol 2006, 74:1173-1179.

72. Liu SL, Huang HC, Yeh ZT, Hwang LC, Tjung JJ, Huang CR, Hsu CC, Ho CJ, Sun IW, Fang CK, Shiau SJ: Controlled trial of problem-solving therapy and consultation-liaison for common mental disorders in general medical settings in Taiwan. Gen Hosp Psychiatry 2007, 29:402-408.

73. Lynch DJ, Tamburrino MB, Nagel R: Telephone counseling for patients with minor depression: preliminary findings in a family practice setting. J Fam Pract 1997, 44:293-298.

74. Lynch D, Tamburrino M, Nagel R, Smith MK: Telephone-based treatment for family practice patients with mild depression. Psychol Rep 2004, 94:785-792.

75. Mynors-Wallis LM, Gath DH, Lloyd-Thomas AR, Tomlinson D: Randomised controlled trial comparing problem solving treatment with amitriptyline and placebo for major depression in primary care. BMJ 1995, 310:441-445.

76. Mynors-Wallis LM, Davies I, Gray A, Barbour F, Gath D: A randomised controlled trial and cost analysis of problem-solving treatment for emotional disorders given by community nurses in primary care. $\mathrm{Br}\lrcorner$ Psychiatry 1997, 170:113-119.

77. Schreuders B, van Marwijk H, Smit J, Rijmen F, Stalman W, van Oppen P: Primary care patients with mental health problems: outcome of a randomised clinical trial. Br J Gen Pract 2007, 57:886-891.

78. Williams JW, Barrett J, Oxman T, Frank E, Katon W, Sullivan M, Cornell J, Sengupta A: Treatment of dysthymia and minor depression in primary care: A randomized controlled trial in older adults. JAMA 2000, 284:1519-1526.

79. Hamilton M: A rating scale for depression. J Neurol Neurosurgical Psychiatry 1960, 23:56-62.

80. Hamilton M: The assessment of anxiety states by rating. Br J Med Psychol 1959, 32:50-55

81. Spek V, Cuijpers P, Nyklicek I, Riper H, Keyzer J, Pop V: Internet-based cognitive behaviour therapy for symptoms of depression and anxiety: a meta-analysis. Psychol Med 2007, 37:319-328.

82. Ekers D, Richards D, Gilbody : A meta-analysis of randomized trials of behavioural treatment of depression. Psychol Med 2008, 38:611-623.

83. Clark DM, Salkovskis PM, Hackmann A, Wells A, Ludgate J, Gelder M: Brief cognitive therapy for panic disorder: a randomized controlled trial. $J$ Consult Clin Psychol 1999, 67:583-589.

84. Wright $\mathrm{BD}$, Linacre JM: Observations are always ordinal; measurements, however must be interval. Arch Phys Med Rehabil 1989, 70:857-860.

85. Kahler E, Rogausch A, Brunner E, Himmel W: A parametric analysis of ordinal quality-of-life data can lead to erroneous results. $J$ Clin Epidemiol 2008, 61:475-480.

86. Grey N, Salkovskis P, Quigley A, Clark DM, Ehlers A: Dissemination of cognitive therapy for panic disorder in primary care. Behav Cog Psychother 2008, 36:509-520.

\section{Pre-publication history}

The pre-publication history for this paper can be accessed here: http://www.biomedcentral.com/1741-7015/8/38/prepub

\section{doi: 10.1186/1741-7015-8-38}

Cite this article as: Cape et al., Brief psychological therapies for anxiety and depression in primary care: meta-analysis and meta-regression BMC Medicine 2010, 8:38

\section{Submit your next manuscript to BioMed Central} and take full advantage of:

- Convenient online submission

- Thorough peer review

- No space constraints or color figure charges

- Immediate publication on acceptance

- Inclusion in PubMed, CAS, Scopus and Google Scholar

- Research which is freely available for redistribution

Submit your manuscript at www.biomedcentral.com/submit
C Biomed Central 